Pablo Vidal-Cortés ${ }^{1}$ Lorena del Río-Carbajo' Jorge Nieto-del Olmo Estefanía Prol-Silva' Ana I. Tizón-Varela' Ana Rodríguez-Vázquez ${ }^{2}$ Pilar Rodríguez-Rodriguez ${ }^{2}$ María D. Díaz-López ${ }^{3}$ Paula Fernández-Ugidos ${ }^{1}$ Marcos A. Pérez-Veloso ${ }^{1}$

\section{COVID-19 and Acute Respiratory Distress Syndrome. Impact of corticosteroid treatment and predictors of poor outcome}

\author{
${ }^{1}$ Intensive Care Unit. Ourense University Hospital \\ ${ }^{2}$ Hospital Pharmacy. Ourense University Hospital \\ ${ }^{3}$ Infectious Diseases Unit. Ourense University Hospital
}

Article history

Received: 9 August 2020; Revision Requested: 29 September 2020; Revision Received: 1 0ctober 2020; Accepted: 6 October 2020; Published: 15 December 2020

\section{ABSTRACT}

Objectives. To assess the impact of corticosteroids on inflammatory and respiratory parameters of patients with COVID-19 and acute respiratory distress syndrome (ARDS).

Methods. Longitudinal, retrospective, observational study conducted in an ICU of a second level hospital. Adult patients with COVID-19 were included. Baseline characteristics, data on SARS-CoV-2 infection, treatment received, evolution of respiratory and inflammatory parameters, and ICU and hospital stay and mortality were analyzed.

Results. A total of 27 patients were included, $63 \%$ men, median age: $68.4(51.8,72.2)$ years. All patients met ARDS criteria and received MV and corticosteroids. After corticosteroids treatment we observed a reduction in the $\mathrm{O}_{2} \mathrm{~A}$-a gradient [day 0: $322(249,425)$; day 3: $169(129.5,239.5) \quad p<0.001$; day 5: $144(127.5,228.0) p<0.001$; day $7: 192(120,261) p=0.002]$ and an increase in the $\mathrm{pO}_{2} / \mathrm{FiO}_{2}$ ratio on days 3 and 5 , but not on day 7 [day 0: $129(100,168)$; day 3: $193(140,236) p=0.002$; day 5: $183(141,255) p=0.004$; day $7: 170(116,251) p=0.057]$. CRP also decreased on days 3 and 5 and increased again on day 7 [day $0: 16(8.6,24)$; day $3: 3.4(1.7,10.2) p<0.001$; day 5 : $4.1(1.4,10.2) p<0.001$; day $7: 13.5(6.8,17.3) p=0.063]$. Persistence of moderate ARDS on day 7 was related to a greater risk of poor outcome (OR 6.417 [1.091-37.735], $p=0.040$ )

Conclusion. Corticosteroids appears to reduce the inflammation and temporarily improve the oxygenation in COVID-19 and ARDS patients. Persistence of ARDS after 7 days treatment is a predictor of poor outcome.

Key words: COVID-19, ARDS, mechanical ventilation, corticosteroids, ICU

Correspondence:

Pablo Vidal-Cortés

Intensive Care Unit CHU Ourense

Ourense University Hospital. Intensive Care Unit. Ramón Puga 52-54. 32005 Ourense (Spain). E-mail: pablo.vidal.cortes@sergas.es
COVID-19 y Síndrome de Distress Respiratorio Agudo. Impacto del tratamiento con corticoides y predictores de mal pronóstico

\section{RESUMEN}

Objetivos. Evaluar el impacto del tratamiento con corticoides en los parámetros inflamatorios y respiratorios de los pacientes con Sindrome de Dificultad Respiratoria Aguda (SDRA) secundario a COVID-19

Métodos. Estudio longitudinal, retrospectivo, observacional en una $\mathrm{UCl}$ de un hospital de segundo nivel. Se incluyeron los pacientes adultos ingresados en UCI por COVID-19. Analizamos caracteristicas basales, datos de la infección por SARS-CoV-2, tratamiento recibido, evolución de los parámetros respiratorios e inflamatorios y estancia y mortalidad en $\mathrm{UCl}$ y hospitalaria.

Resultados. 27 pacientes, 63\% hombres, mediana de edad: $68.4(51.8,72.2)$ años. Todos recibieron ventilación mecánica y cumplieron criterios de SDRA. Todos recibieron corticoides. Tras la administración de corticoides observamos una reducción del gradiente $\mathrm{A}$-a de $\mathrm{O}_{2}$ [día 0: $322(249,425) ;$ día 3: 169 (129.5, 239.5) $p<0.001$; día 5: $144(127.5,228.0) p<0.001$; día 7: 192 $(120,261) p=0.002]$ y un aumento en la relación $\mathrm{pO}_{2} / \mathrm{FiO}_{2}$ en los días 3 y 5, pero no al día 7 [día 0: $129(100,168)$; día 3: $193(140$, 236) $p=0.002$; día 5: $183(141,255) p=0.004$; día 7: $170(116$, 251) $p=0.057$ ]. La PCR descendió a los días 3 y 5 volviendo a subir al día 7 [día 0: $16(8.6,24)$; día 3: $3.4(1.7,10.2) p<0.001$; día 5: $4.1(1.4,10.2) p<0.001$; día 7: $13.5(6.8,17.3) p=0.063]$. La persistencia de SDRA moderado al día 7 se relacionó con un peor pronóstico (OR 6.417 [1.091-37.735], p=0.040)

Conclusión. Los corticosteroides parecen reducir la inflamación y mejorar temporalmente la oxigenación en pacientes con SDRA y COVID-19. La persistencia de SDRA moderado tras 7 dias de tratamiento es un predictor de mal pronóstico.

Palabras clave: COVID-19, SDRA, ventilación mecánica, UCl, corticosteroides, ICU 


\section{INTRODUCTION}

On 11 March 2020 the World Health Organization announced that the outbreak of the disease caused by coronavirus SARS-CoV-2 (severe acute syndrome coronavirus 2), known as COVID-19, can be characterized as a pandemic, after having first appeared in late 2019 in China.

COVID-19 has been a challenge for health systems all over the world; especially for ICUs that have had to expand to assume a number of patients that exceeded the number of beds available. At the same time, the lack of a known, effective treatment has led to a spate of treatment recommendations [1-4], which are not always backed by sufficient scientific evidence [5].

It has been suggested that the clinical course of COVID-19 evolves over several phases. The initial phase would be marked by a high viral load. The subsequent inflammatory response (evaluated by means of determination of interleukins but also estimated using $\mathrm{C}$ reactive protein [CRP], lactate dehydrogenase [LDH], D-dimer, ferritin, etc.) would be the cause of clinical worsening in some patients [6] This theory has not been confirmed and other researchers have cast doubt about the existence and importance of the "cytokine storm"[7].

According to this theory, different treatments targeted at modulating the inflammatory response, including corticosteroids, have been suggested. In a retrospective analysis of 84 patients with COVID-19 and ARDS (treated at one hospital in Wuhan) lower mortality was observed in those patients who had received methylprednisolone ( $\mathrm{HR} 0.38 ; 95 \% \mathrm{Cl} 0.20-0.72$ ) [8]. The recommendation to administer corticosteroids early during moderate-severe ARDS [9] carries more weight after publication of the results of a randomized clinical trial in which dexamethasone was shown to reduce the duration of mechanical ventilation (MV) and the mortality, compared to routine intensive care [10]. Data also exist that suggest a benefit of corticosteroid treatment in patients with community-acquired pneumonia and an intense inflammatory response [11] and, even, in patients with influenza-related pneumonia and ARDS [12]. However, unfavorable results have been notified in patients with respiratory infections of viral etiology, such as MERS (Middle East Respiratory Syndrome) [13] and also in influenza-related pneumonia $[14,15]$, which means we must be circumspect with its administration [16].

The Surviving Sepsis Campaign suggests using systemic corticosteroids in patients subjected to MV and ARDS following COVID-19 [2].

Recently, results of RECOVERY clinical trial have showed that use of dexamethasone resulted in lower 28-day mortality among COVID-19 patients who were receiving invasive mechanical ventilation [17].

The main objective of our study is to analyze the effects of a short course of corticosteroids on the respiratory and inflammatory parameters of patients undergoing MV because of ARDS following COVID-19. Our secondary objective is to identify predictors of poor outcome (death or prolonged MV).

\section{MATERIAL AND METHODS}

Scope of study. A second level Spanish hospital ICU with 22 beds (14 of which are suitable for patients on MV). Patients received treatment in accordance with our center's protocol, which included a recommendation for methylprednisolone $(0.5 \mathrm{mg} / \mathrm{kg} / 12$ hours, 3 days) if the patient was receiving MV and complied with ARDS criteria [18]. Our protocol recommended performing a control PCR for SARS-CoV-2 10 days from admission (if the patient had no fever); in the event of a positive result a new test at 5 days was recommended.

Study period. Patients admitted during the first wave of the COVID-19 pandemic (March-June 2020).

Study design. Longitudinal, retrospective, observational study.

Inclusion criteria. Adult patients admitted to the ICU because of respiratory failure secondary to COVID-19, diagnosed by a positive PCR for SARS-CoV-2.

Exclusion criteria. Not applicable.

Ethical aspects. The study was approved by the Galicia Ethics Committee for Research into Medicines (CElm-G) (code 2020/246).

Measures. We assessed sociodemographic data (age and sex), comorbidities, data on SARS-CoV-2 infection (duration of the disease at admission, time until a negative PCR test for SARS-CoV-2), severity scores at admission (SOFA and APACHE II), treatments received, respiratory support, evolution of respiratory and inflammatory parameters during the first week of MV and duration of the MV and ICU and hospital stay; in addition to the incidence of coinfections at admission and superinfections during stay in the ICU (defined by positive cultures and/or significant elevation in procalcitonin: $\geq 0.5 \mathrm{ng} / \mathrm{mL}$ ).

Comorbidities were recorded according to the data obtained from the clinical history. They were grouped according to the system affected: cardiovascular (history of ischemic cardiopathy, heart failure or severe valvular disease), respiratory (diagnosis of COPD or asthma), central nervous system (history of cerebrovascular disease with or without sequelae), and liver (cirrhosis at any stage). Hematologic malignancy included those patients with a history of any kind of leukemia or lymphoma, regardless of time from diagnosis. Cancer included those patients who had received treatment for their neoplasia in the last 5 years.

Patients who needed MV for 21 days or less were classified as Group A (good outcome). Patients who died or needed MV for more than 21 days were classified as Grupo B (poor outcome).

The main objective was to analyze evolution of respiratory $\left(\mathrm{pO}_{2} / \mathrm{FiO}_{2}\right.$ ratio and $\mathrm{O}_{2}$ alveolo-arterial gradient) and inflammatory parameters (CRP, LDH, D-dimer, ferritin, lymphocyte count) after administration of corticosteroids. To homogenize our data, we used arterial blood gas results obtained daily while the patient was in supine position. We consider resolution of moderate ARDS when the $\mathrm{pO}_{2} / \mathrm{FiO}_{2}$ ratio remained above 200 for at least 48 hours. 
Our secondary objective was to identify the variables present at admission or during the first week under MV that predict a poor outcome (death or need for MV for more than 21 days). We evaluated the existence of a relationship between the poor result and the main inflammatory and respiratory parameters, viral persistence and the presence of coinfection upon admission to the ICU.

Statistical analysis. Continuous variables are shown as median and p25, p75; qualitative variables are shown as number and percentage. To compare medians, we used the Mann-Whitney $\mathrm{U}$ test, and we compared percentages using the chi-squared test. We used logistic regression to assess the relationship between the risk of poor outcome and the variables selected. We have assumed an $\alpha$ error of 0.05 . We used the statistical software package IBM SPSS Statistics, Version 19.0 (IBM Corp., Armonk, NY, USA) for statistical analysis and to plot graphs.

\section{RESULTS}

Up to June 16, 2020, 27 patients were admitted to our center's COVID-ICU. 63\% were men and their median age was $68.4(51.8,72.2)$ years. Comorbidities and basal characteristics of patients are shown in Table 1.

Figure 1 summarizes both MV and ICU and hospital stay times for each patient.

Patients were admitted to the ICU after spending a median of $3(1,4)$ days on the hospital; $4(2.2,7.7)$ days in Group A $(0,3)$ and $2(0,3)$ days in Group $B_{1}(p=0.047)$. Both antiviral and anti-inflammatory treatment received by patients are summarized in Table 2.

All patients received MV and 15 patients (55.5\%) received non-invasive ventilation (NIV) prior to onset of MV. Parameters related to respiratory support are shown in Table 3.

Ferritin levels at the time of onset of MV were 548 (280.5, 1970.5) mg/mL, $282(220,2281)$ in Group $A$ and 1151 (496.2, 2108.2) in Group B ( $p=0.242)$.

A total of $12(44.4 \%)$ patients presented a positive control SARS-CoV-2 PCR; 7 (58.3\%) patients in Group A and 5 (33.3\%) patients in Group B $(p=0.194) .6(22.2 \%)$ patients presented two positive control SARS-CoV-2 PCR; 4 (33.3\%) patients in Group A and 2 (13.3\%) patients in Group B ( $p=0.214)$, and four patients did not have a negative control PCR before leaving hospital (14.8\%), 3 (25\%) patients in Group A and 1 (6.7) patient in Group B ( $p=0.183)$.

A total of 27 patients (100\%) complied with ARDS criteria at the time of starting MV and received treatment with 0.5 $\mathrm{mg} / \mathrm{kg} / 12 \mathrm{~h}$ of methylprednisolone. Treatment lasted $3(3,4)$ days, with a median of $3(2,4)$ in Group A patients and $3(3$, $4.2)$ in Group B patients ( $p=0.294)$.

Corticosteroids was started at the same time as mechanical ventilation in 26 patients $(96,3 \%)$. Figure 2 shows the evolution of inflammatory and respiratory parameters from starting corticosteroid treatment to day 28 , and Table 4 shows the comparison of baseline values with those measured on days 3,5 and 7 after starting corticosteroids. We have not made comparisons beyond the seventh day due to the small number of patients and high variability, which is probably related to the presence or absence of complications, especially infectious complications.

Figure 3 shows the evolution of inflammatory and respiratory parameters in group $A$ and group $B$ patients. In table 5 we compare those parameters in group $A$ and group $B$ patients on admission and on days 3, 5 and 7, in order to explore early differences between the two groups.

When we searched for factors that predict poor outcome (death or need for prolonged MV) during the first week of MV, we found that only moderate ARDS criteria persisting 7 days from MV onset predicts a poor outcome (OR: 6.417, 95\% Cl 1.091-37.735, $p=0.040$ ) (Table 6).

\section{DISCUSSION}

In this study we describe 27 patients admitted to our ICU because of COVID-19 from March to June 2020. A total of 1880 cases were diagnosed in our healthcare area up to June 16 (approximate incidence of 652 cases per 100,000 inhabitants); of these 132 died (7.0\%). ICU admission represents 1.4\% of all cases diagnosed and 5.1\% of COVID-19-related hospital admissions. The percentage of patients admitted to the ICU is far from the $11.3 \%$ reported by Rodriguez et al. [19], although close to the 7\% published by Yang et al [20].

The sample is a predominantly male population with few comorbidities. Our data are similar to other series published on critically ill COVID-19 patients, although the median age and percentage of patients with onco-hematologic diseases is slightly higher in our study [19-26].

The role of NIV in these patients has been a moot point during the pandemic; both because of the high rate of failure and the risk of infecting healthcare staff. In over half our patients (55.6\%) NIV was tested and failed; MV was required in $100 \%$ of patients. Other authors have reported high levels of failure of NIV: $85.2 \%$ in the Tarragona study [19]. In the Lombardy and Washington series barely 11\% and 19\% respectively only received NIV, while the number of patients receiving MV after having received NIV is not specified [25] and Hua et al. report $32.5 \%$ of patients treated with NIV. None of the studies published to date attain 100\% of patients under MV. However, the Vitoria study exceeds 90\% [22] and both the Lombardy and Tarragona studies are close (88\% and $86 \%$, respectively) [19, 25]. At the other extreme, just $24 \%$ of patients from the Hua et al. series and $42 \%$ of the Yang et al. series received MV [20, 26].

The severity of respiratory failure is notable (median $\mathrm{pO}_{2} / \mathrm{FiO}_{2}$ ratio of 129 , and $\mathrm{O}_{2} \mathrm{~A}$-a gradient of $322 \mathrm{mmHg} \mathrm{O}_{2}$, at $\mathrm{MV}$ onset) with a high percentage of patients meeting moderate (88.9\%) and severe (25.9\%) ARDS criteria. Only Yang et al. have observed a lower $\mathrm{pO}_{2} / \mathrm{FiO}_{2}$ ratio, however, they report that only $67 \%$ of patients comply with ARDS criteria and just $42 \%$ of their patients 


\begin{tabular}{|c|c|c|c|c|}
\hline \multirow[t]{2}{*}{ Table 1} & \multicolumn{4}{|c|}{ Comorbidities, basal characteristics, evolution and results } \\
\hline & Overall & Group A & Group B & $p$ \\
\hline$n$ & 27 & 12 & 15 & \\
\hline Male sex & $17(63)$ & $7(58.3)$ & $10(66.7)$ & 0.656 \\
\hline Age & $68.4(51.8,72.2)$ & $60.1(45.2,71.9)$ & $70.8(58.7,72.9)$ & 0.841 \\
\hline \multicolumn{5}{|l|}{ Comorbidities } \\
\hline Arterial hypertension & $11(40.7)$ & $6(50)$ & $5(33.3)$ & 0.381 \\
\hline Dyslipidemia & $11(40.7)$ & $5(41.7)$ & $6(40)$ & 0.930 \\
\hline Diabetes mellitus & $5(18.5)$ & $1(8.3)$ & $4(26.7)$ & 0.223 \\
\hline Cardiovascular & $1(3.7)$ & $1(8.3)$ & 0 & 0.255 \\
\hline Respiratory & $5(18.5)$ & $1(8.3)$ & $4(26.7)$ & 0.233 \\
\hline CNS & $1(3.7)$ & 0 & $1(6.7)$ & 0.362 \\
\hline Liver & $2(7.4)$ & $1(8.3)$ & $1(6.7)$ & 0.869 \\
\hline Hematologic malignancy & $2(7.4)$ & $2(16.7)$ & 0 & 0,100 \\
\hline Cancer & $3(11.1)$ & $2(16.7)$ & $1(6.7)$ & 0.411 \\
\hline BMI & $28.5(25.2,32.6)$ & $29.0(25.5,34.2)$ & $27.4(25.2,31.3)$ & 0.902 \\
\hline \multicolumn{5}{|l|}{ Disease course and duration } \\
\hline Ss-H admission (d) & $7.0(3.5,9.0)$ & $5(2,8)$ & $7(4.75,10)$ & 0.798 \\
\hline Ss-ICU admission (d) & $10(7.0,12.5)$ & $10(9,12)$ & $9.5(7,13.2)$ & 0.063 \\
\hline Ss-MV onset (d) & $12(9,14)$ & $12(10,13)$ & $11.5(8.5,14.2)$ & 0.056 \\
\hline Days PCR + until PCR - & $21(16,29)$ & $21(10.5,38.5)$ & $22.5(18.5,27.5)$ & 0.419 \\
\hline Symptoms until PCR - (d) & $33(28,36)$ & $34.5(21.7,46.2)$ & $31(28,36)$ & 0.943 \\
\hline \multicolumn{5}{|l|}{ Severity scores } \\
\hline APACHE II & $14(10,17)$ & $14(9.2,17.7)$ & $14(11,17)$ & 0.580 \\
\hline SOFA $24 \mathrm{~h}$ & $4(4,7)$ & $5.5(4,6.7)$ & $4(4,7)$ & 0.092 \\
\hline \multicolumn{5}{|c|}{ Oxygenation parameters at the onset of mechanical ventilation } \\
\hline $\mathrm{pO}_{2} / \mathrm{FiO}_{2}<300$ & $27(100)$ & & & \\
\hline $\mathrm{pO}_{2} / \mathrm{FiO}_{2}<200$ & $24(88.9)$ & $10(83.3)$ & $14(93.3)$ & 0.411 \\
\hline $\mathrm{pO}_{2} / \mathrm{FiO}_{2}<100$ & $7(25.9)$ & $3(25)$ & $4(26.7)$ & 0.922 \\
\hline \multicolumn{5}{|c|}{ Coinfection and superinfection in the ICU } \\
\hline Coinfection & $13(48.1)$ & $5(41.7)$ & $8(53.3)$ & 0.547 \\
\hline Superinfection & $18(66.7)$ & $4(33.3)$ & $14(93.3)$ & 0.001 \\
\hline MV onset-superinfec (d) & $14(8.7,22.2)$ & $10.5(8.5,11)$ & $17(8.7,23.5)$ & 0.151 \\
\hline \multicolumn{5}{|l|}{ Results } \\
\hline Deceased at $28 \mathrm{~d}$ & $2(7.4)$ & $0(0)$ & $2(13.3)$ & 0.189 \\
\hline Under MV at $28 \mathrm{~d}$ & $10(37)$ & 0 & $10(66.7)$ & $<0.001$ \\
\hline ICU at $28 \mathrm{~d}$ & $12(44.4)$ & 0 & $12(80)$ & $<0.001$ \\
\hline Hospital ward at $28 \mathrm{~d}$ & $12(44.4)$ & $11(91.7)$ & $1(6.7)$ & $<0.001$ \\
\hline Home at $28 \mathrm{~d}$ & $1(3.7)$ & $1(8.3)$ & 0 & 0.255 \\
\hline ICU mortality & $3(11.1)$ & 0 & $3(21.4)$ & 0.088 \\
\hline ICU LOS & $26(19,39)$ & $19(10.2,23.5)$ & $35(28,45)$ & $<0.001$ \\
\hline Hospital LOS & $47(35,54)$ & $41(35.7,47.5)$ & $53(35,58)$ & 0.067 \\
\hline
\end{tabular}

CNS: central nervous system, BMI: body mass index, Ss: symptoms, H: hospital, MV: mechanical ventilation, d: days, LOS: length of stay. 


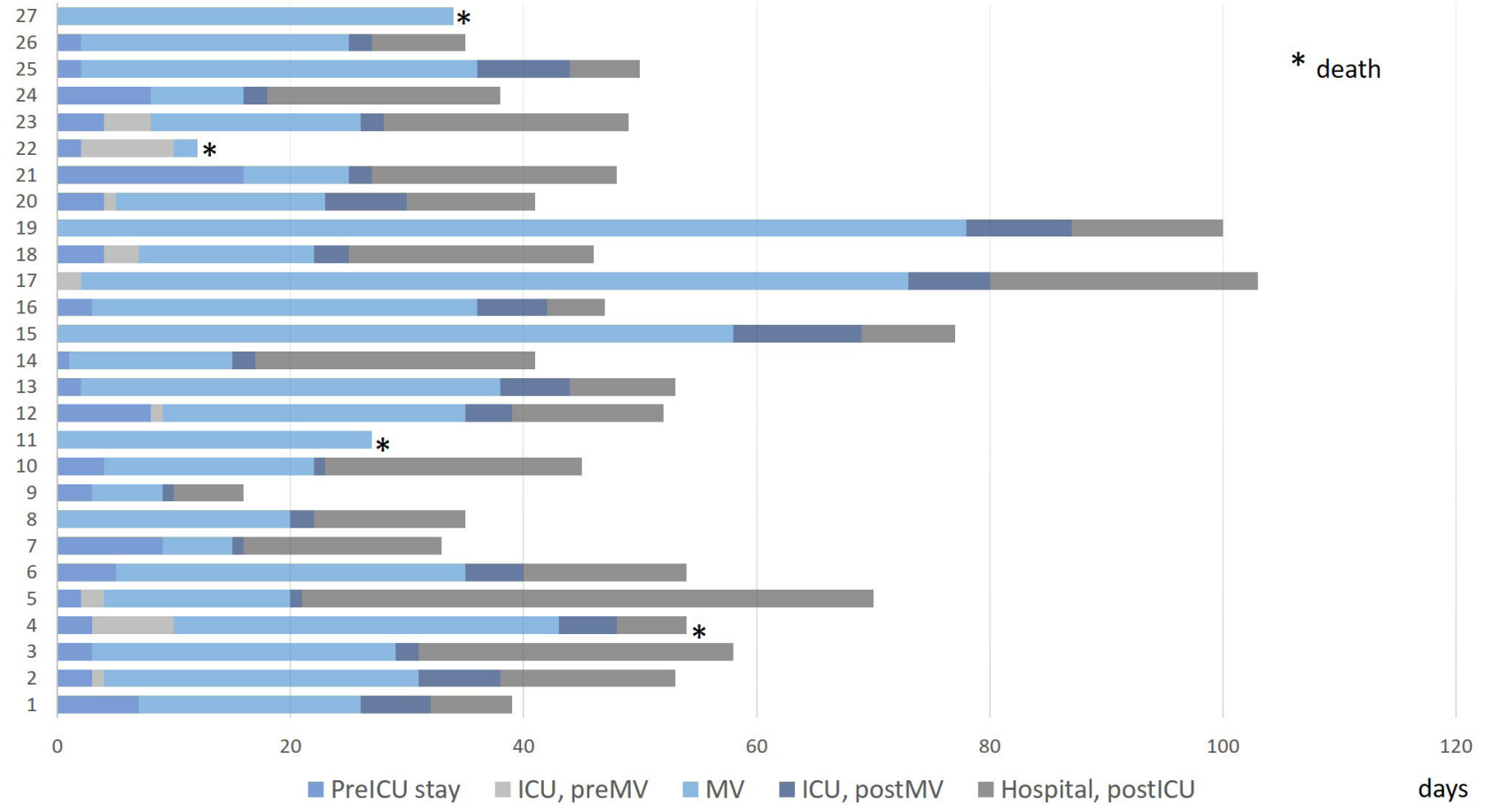

Figure 1 Mechanical ventilation and ICU and hospital stay times for each patient (MV: mechanical ventilation; ICU: intensive care unit)

\begin{tabular}{|c|c|c|c|c|c|}
\hline \multirow[t]{2}{*}{ Table 2} & \multicolumn{5}{|c|}{ Treatment received } \\
\hline & & Overall & Group A & Group B & p \\
\hline \multicolumn{2}{|c|}{ Lopinavir-ritonavir } & $20(74.1)$ & $10(83.3)$ & $10(66.7)$ & 0.326 \\
\hline \multicolumn{2}{|c|}{ Interferon B-1b } & $11(40.7)$ & $6(50)$ & $5(33.3)$ & 0.381 \\
\hline \multicolumn{2}{|c|}{ Corticosteroid bolus (prelCU) } & $6(22.2)$ & $2(16.7)$ & $4(26.7)$ & 0.535 \\
\hline \multicolumn{2}{|c|}{ Tocilizumab (prelCU) } & $3(11.1)$ & $2(16.7)$ & $1(6.7)$ & 0.411 \\
\hline \multicolumn{2}{|c|}{ Tocilizumab (in ICU) } & $8(29.6)$ & 0 & $8(53.3 \%)$ & 0.003 \\
\hline \multicolumn{2}{|c|}{ Hydroxychloroquine } & $27(100)$ & & & \\
\hline \multicolumn{2}{|c|}{ Methylprednisolone } & $27(100)$ & & & \\
\hline \multicolumn{2}{|c|}{ Days methylprednisolone } & $3(3,4)$ & $3(2,4)$ & $3(3,4.2)$ & 0.294 \\
\hline \multicolumn{2}{|l|}{ Antibiotic } & $27(100)$ & & & \\
\hline
\end{tabular}

receive MV. For the remaining series, the $\mathrm{pO}_{2} / \mathrm{FiO}_{2}$ ratio at the onset of MV varies between 130 and 169, and incidence of ARDS is around $70 \%$. In our series, 55\% of patients continue to comply with moderate ARDS criteria after 7 days under MV. Median time until a $\mathrm{pO}_{2} / \mathrm{FiO}_{2}$ ratio above of 200 is 9 days. The severity of respiratory failure of our patients is also reflected in the percentage of patients requiring ventilation in prone position (96.3\%), in the high number of sessions they received, with a median of 7, and the duration of MV (median 23 days); only the Blake et al. and
Rodriguez et al. series are close, with 79\% and 82\%, respectively, of patients that receive ventilation in prone position. The remaining series vary between 11.5\% [20] and 50\% [22,23].

Contrary to the severity of respiratory failure, we have barely observed other cases of organ failure, as reflected in the median SOFA score: $4(4,7)$. Both the Vitoria and Tarragona studies reported a higher score (7 and 6, respectively) $[19,22]$ and Yang et al. published an incidence of renal failure and liver dysfunction of $29 \%$ [20]. 


\begin{tabular}{lcccc}
\hline Table 3 & \multicolumn{1}{|l}{ Respiratory therapy } & & \\
& & & & \\
& Overall & Group A & Group B & $p$ \\
\hline NIV & $15(55.6)$ & $8(66.7)$ & $7(46.7)$ & 0.299 \\
\hline Days NIV & $1(0,3)$ & $0.5(0,2.7)$ & $1(0,7)$ & 0.435 \\
\hline MV & $27(100)$ & & & \\
\hline Days MV & $23(15,33)$ & $15.5(8.2,18)$ & $33(26,36)$ & $<0.001$ \\
\hline Prone ventilation & $26(96.3)$ & $11(91.7)$ & $15(100)$ & 0.255 \\
\hline Prone vent sessions & $7(4.7,9.2)$ & $6(3,8)$ & $7(5,17)$ & 0.076 \\
\hline $\mathrm{pO}_{2} /$ Fi ${ }_{2}<200$ at $7 \mathrm{~d}$ & $15(55.5)$ & $4(36.4)$ & $11(78.6)$ & 0.032 \\
\hline Days moderate ARDS & $9(4,16)$ & $5(2.2,12.7)$ & $15(9,21)$ & 0.014 \\
\hline Tracheotomy & $12(44.4)$ & 0 & $12(80)$ & $<0.01$ \\
\hline
\end{tabular}

NIV: non-invasive respiratory support, MV: mechanical ventilation, d: days
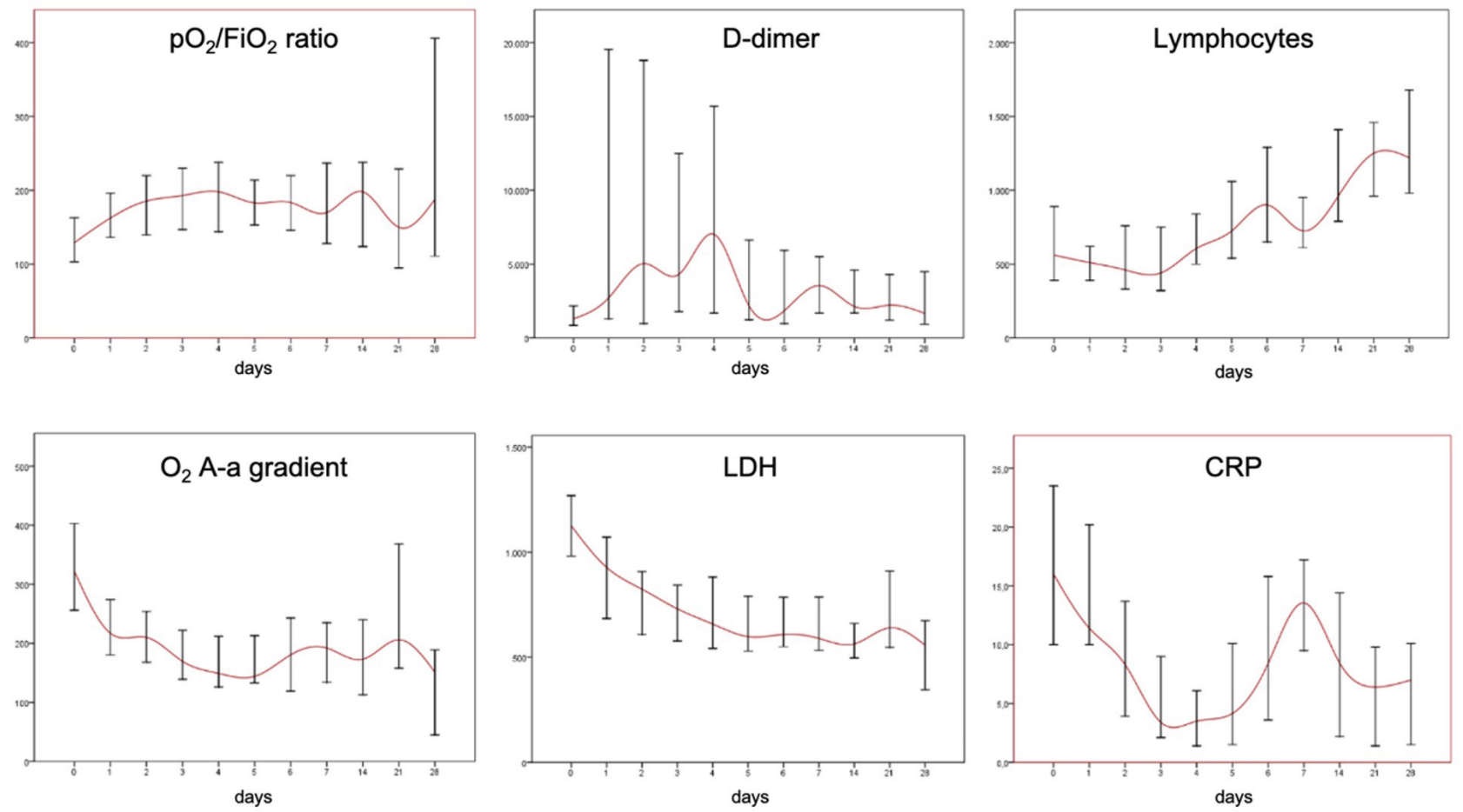

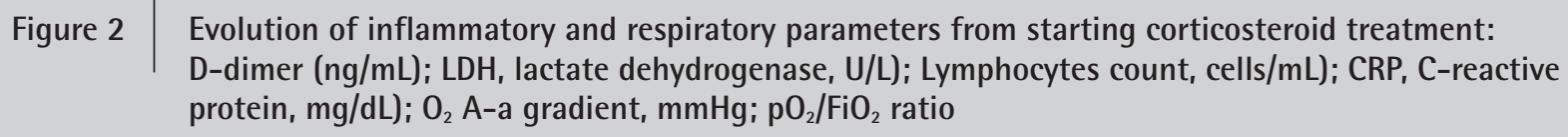

Barrasa et al. and Rodriguez et al. [19,22] reviewed treatments administered to their patients. In both studies and ours, treatment most commonly administered were hydroxychloroquine (>90\%) and lopinavir-ritonavir (74.1\% in our case, above the $90 \%$ in the other two series). Less homogeneous is the interferon $\beta-1 \mathrm{~B}$ treatment, received by less than $50 \%$ of patients from Rodríguez et al's. study and ours, and $85 \%$ of patients from the Barrasa et al. series; and tocilizumab treatment (40.7\% in our study, less than 5\% in the other two). All our patients received corticosteroids after onset of $\mathrm{MV}$, as opposed to $35 \%$ of the Vitoria et al. study, 2.3\% of the Tarragona study, and 58\% of patients from the Yang et al. study $[19,20,22]$.

When attempting to evaluate the impact of the treatment with corticosteroids, we observed a significant reduction in 


\begin{tabular}{|c|c|c|c|c|c|}
\hline \multirow[t]{2}{*}{ Table 4} & \multicolumn{5}{|c|}{ Evolution of respiratory and inflammatory parameters } \\
\hline & & Day 0 & Day 3 & Day 5 & Day 7 \\
\hline \multirow{3}{*}{$\begin{array}{l}\text { D-dimer } \\
\text { (ng/mL) }\end{array}$} & Value & 1290 & 4308 & 2166.5 & 3541 \\
\hline & & $(843,2865.5)$ & $(1776,12485)$ & $(1228.2,8281.2)$ & $(1673,5507)$ \\
\hline & $\mathrm{p}$ (compared to day 0 ) & & 0.067 & 0.096 & 0.033 \\
\hline \multirow{3}{*}{$\begin{array}{l}\text { LDH } \\
\text { (U/L) }\end{array}$} & Value & 1126 & 730.5 & 598.5 & 590.0 \\
\hline & & $(817.5,1361)$ & $(542,871.7)$ & $(528.2,793.5)$ & $(525.5,800)$ \\
\hline & $p$ (compared to day 0 ) & & $<0.001$ & $<0.001$ & $<0.001$ \\
\hline \multirow{3}{*}{$\begin{array}{l}\text { Lymphs count } \\
\text { (cells/mL) }\end{array}$} & Value & 560 & 440 & 725 & 725 \\
\hline & & $(380,900)$ & $(315,800)$ & $(518.7,1182.5)$ & $(540.9,1122.5)$ \\
\hline & $p$ (compared to day 0 ) & & 0.296 & 0.078 & 0.031 \\
\hline \multirow{3}{*}{$\begin{array}{l}\text { CRP } \\
(\mathrm{mg} / \mathrm{dL})\end{array}$} & Value & 16 & 3.4 & 4.1 & 13.5 \\
\hline & & $(8.6,24.0)$ & $(1.7,10.2)$ & $(1.4,10.2)$ & $(6.8,17.3)$ \\
\hline & $p$ (compared to day 0 ) & & $<0.001$ & $<0.001$ & 0.063 \\
\hline \multirow{3}{*}{$\begin{array}{l}\mathrm{O}_{2} \mathrm{~A}-\mathrm{a} \text { grad } \\
(\mathrm{mmHg})\end{array}$} & Value & 322 & 169 & 144 & 192 \\
\hline & & $(249,425)$ & $(129.5,239.5)$ & $(127.5,228.0)$ & $(120,261)$ \\
\hline & $p$ (compared to day 0 ) & & $<0.001$ & $<0.001$ & 0.002 \\
\hline \multirow[t]{3}{*}{$\mathrm{pO}_{2} / \mathrm{FiO}_{2}$} & Value & 129 & 193 & 183 & 170 \\
\hline & & $(100,168)$ & $(140,236)$ & $(141,255)$ & $(116,251)$ \\
\hline & $\mathrm{p}$ (compared to day 0 ) & & 0.002 & 0.004 & 0.057 \\
\hline
\end{tabular}

LDH: lactate dehydrogenase, lymphs: lymphocytes, CRP: C reactive protein, grad: gradient
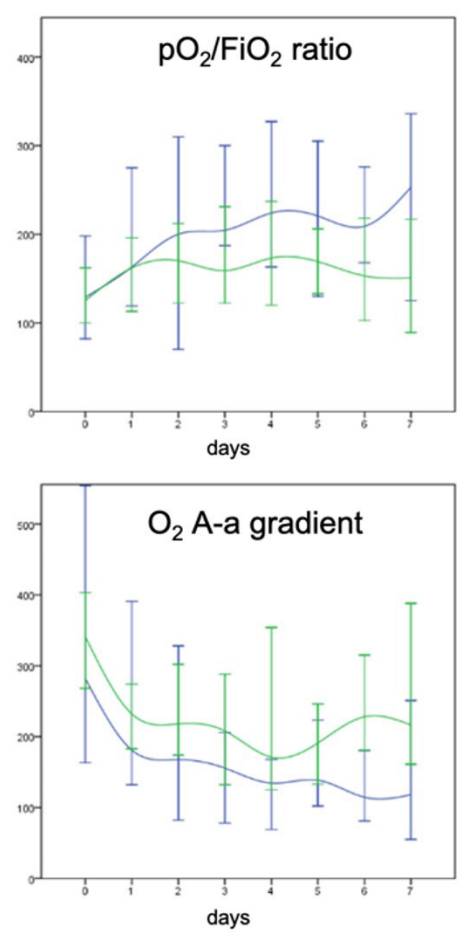

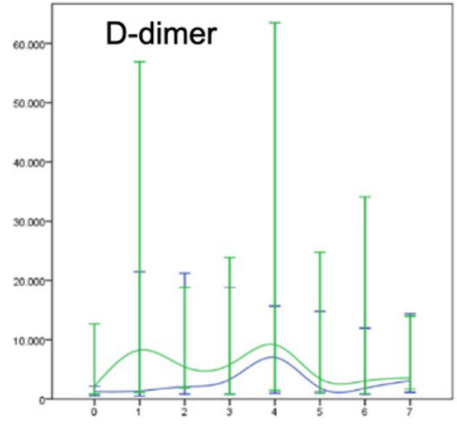

days

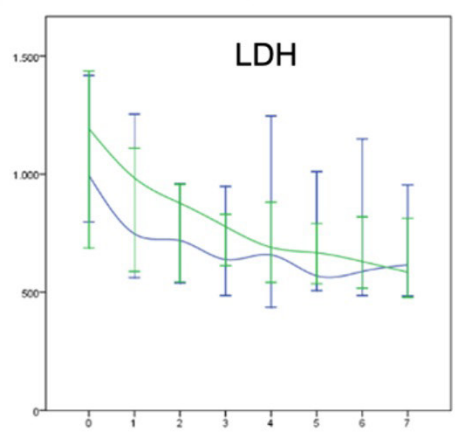

days

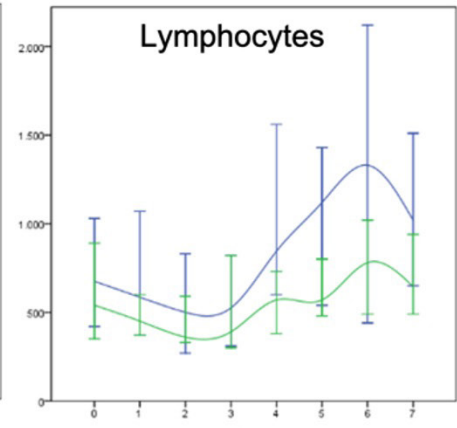

days

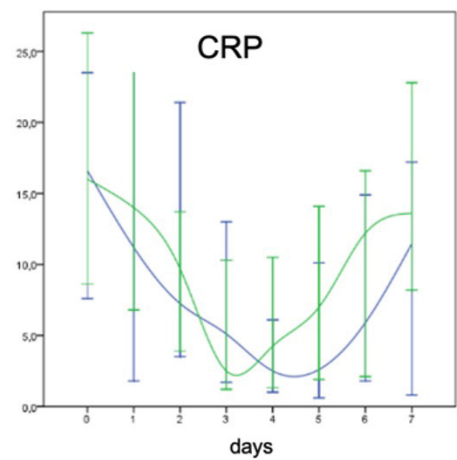

I Group A I Group B

Figure 3 Evolution of inflammatory and respiratory parameters in group A and group B patients: D-dimer $(\mathrm{ng} / \mathrm{mL}) ; \mathrm{LDH}$, lactate dehydrogenase, U/L); Lymphocytes count, cells $/ \mathrm{mL}) ; \mathrm{CRP}, \mathrm{C}$-reactive protein, $\mathrm{mg} / \mathrm{dL}) ; \mathrm{O}_{2} \mathrm{~A}$-a gradient, $\mathrm{mmHg} ; \mathrm{pO}_{2} / \mathrm{FiO}_{2}$ ratio 


\begin{tabular}{|c|c|c|c|c|c|}
\hline \multirow[t]{2}{*}{ Table 5} & \multicolumn{5}{|c|}{$\begin{array}{l}\text { Comparison of the evolution in respiratory and inflammatory } \\
\text { parameters between Group A and B }\end{array}$} \\
\hline & & Day 0 & Day 3 & Day 5 & Day 7 \\
\hline \multirow{5}{*}{$\begin{array}{l}\text { D-dimer } \\
(\mathrm{ng} / \mathrm{mL})\end{array}$} & Group A & 1290 & 3321 & 1874 & 3082 \\
\hline & & $(663,2028)$ & $(1806,9177)$ & $(1228.2,13631.7)$ & $(1226.7,5503.2)$ \\
\hline & Group B & 2797 & 9144 & 3435 & 3541 \\
\hline & & $(862,10437)$ & $(1504.5,21219.7)$ & $(1217.7,4741)$ & $(1788,11450)$ \\
\hline & $p$ & 0.099 & 0.462 & 1 & 0.563 \\
\hline \multirow{5}{*}{$\begin{array}{l}\mathrm{O}_{2} \mathrm{~A}-\mathrm{a} \\
\text { grad }\end{array}$} & Group A & 282 & 155.5 & 138.5 & 118 \\
\hline & & $(166.7,521.7)$ & $(83.5,205.5)$ & $(103.2,208.5)$ & $(70,225)$ \\
\hline & Group B & 341 & 191 & 191 & 216.5 \\
\hline & & $(268,403)$ & $(136.5,239.5)$ & $(136.5,239.5)$ & $(170,340)$ \\
\hline & $p$ & 0.626 & 0.190 & 0.157 & 0.006 \\
\hline \multirow{5}{*}{$\begin{array}{l}\text { LDH } \\
(U / L)\end{array}$} & Group A & 995.5 & 638.5 & 569.5 & 616 \\
\hline & & $(804.5,1363.5)$ & $(497,941.2)$ & $(511.7,959.2)$ & $(522.2,943.5)$ \\
\hline & Group B & 1205 & 778 & 667 & 585 \\
\hline & & $(1019,1345)$ & $(618,820.2)$ & $(557,785.5)$ & $(518,787)$ \\
\hline & $p$ & 0.495 & 0.954 & 0.644 & 0.439 \\
\hline \multirow{5}{*}{$\begin{array}{l}\text { Lymphs count } \\
\text { (cells/mL) }\end{array}$} & Group A & 675 & 525 & 1120 & 1020 \\
\hline & & $(427.5,997.5)$ & $(312.5,810)$ & $(590,1420)$ & $(665,1440)$ \\
\hline & Group B & 540 & 390 & 570 & 645 \\
\hline & & $(350,890)$ & $(310,785)$ & $(506.2,762.5)$ & $(497.5,880)$ \\
\hline & $p$ & 0.421 & 0.785 & 0.040 & 0.051 \\
\hline \multirow[t]{5}{*}{$\mathrm{pO}_{2} / \mathrm{FiO}_{2}$} & Group A & 129 & 204.5 & 220.5 & 253 \\
\hline & & $(87.5,191.5)$ & $(189.7,290)$ & $(135,296.2)$ & (145.332) \\
\hline & Group B & 125 & 159 & 169 & 150.5 \\
\hline & & $(100,162)$ & $(125,227.2)$ & $(143,205.5)$ & $(97.2,187.7)$ \\
\hline & $p$ & 0.660 & 0.051 & 0.211 & 0.027 \\
\hline \multirow{5}{*}{$\begin{array}{l}\text { CRP } \\
(\mathrm{mg} / \mathrm{dL})\end{array}$} & Group A & 16.6 & 5.1 & 2.6 & 11.4 \\
\hline & & $(8.2,22.9)$ & $(2,12.3)$ & $(1.2,9)$ & $(1.2,16.6)$ \\
\hline & Group B & 16 & 2.5 & 7 & 13.6 \\
\hline & & $(8.6,26.3)$ & $(1.5,9)$ & $(2,13.6)$ & $(9.5,21.1)$ \\
\hline & $p$ & 0.626 & 0.498 & 0.224 & 0.190 \\
\hline
\end{tabular}

Grad: gradient, LDH: lactate dehydrogenase, lymphs: lymphocytes, CRP: C reactive protein

$\mathrm{LDH}, \mathrm{CRP}$ and $\mathrm{O}_{2} \mathrm{~A}-\mathrm{a}$ gradient, in addition to an increase in $\mathrm{pO}_{2} / \mathrm{FiO}_{2}$ ratio. CRP levels decreased initially and went up again once methylprednisolone treatment ended. No statistically significant differences between median CRP on day 7 and at onset of treatment were detected. The $\mathrm{pO}_{2} / \mathrm{FiO}_{2}$ ratio also increased initially and then reduced until there were no statistically significant differences between days 0 and 7 of MV. These trends appear to coincide with the time when patients received methylprednisolone; given the results of clinical trials with lopinavir-ritonavir and hydroxychloroquine [27-29], it does not appear that this effect can be attributed to the remaining treatments received by our patients. On the other hand, the initial favorable course with subsequent worsening leads us to suspect that this is not natural disease course, but rather can be impacted by the administration of methylprednisolone. Wu et al. observed that patients with COVID-19 and ARDS who had received methylprednisolone presented longer survival [8], and preliminary results of RECOVERY trial show that low doses of dexamethasone reduce the mortality of COVID-19 patients that require respiratory support, especially MV [17] 


\begin{tabular}{|c|c|c|c|c|}
\hline \multirow[t]{2}{*}{ Table 6} & \multicolumn{4}{|c|}{ Poor outcome predictors. Univariate analysis } \\
\hline & & $O R$ & $\mathrm{Cl}$ & p \\
\hline \multicolumn{2}{|c|}{ Positive control PCR } & 2.8 & $0.582-13.478$ & 0.199 \\
\hline \multicolumn{2}{|c|}{ Positive control PCR $\times 2$} & 3.25 & $0,480-21,997$ & 0.227 \\
\hline \multicolumn{2}{|c|}{ Coinfection on admission } & 1.6 & $0.346-7.401$ & 0.548 \\
\hline \multicolumn{2}{|c|}{ Severe ARDS day 0 MV } & 2.8 & $0.222-35.288$ & 0.426 \\
\hline \multicolumn{2}{|c|}{ Moderate ARDS day $0 \mathrm{MV}$} & 1.091 & $0.192-6.196$ & 0,922 \\
\hline \multicolumn{2}{|c|}{ Moderate ARDS day 7 MV } & 6.417 & $1.091-37.735$ & 0.040 \\
\hline \multicolumn{2}{|c|}{$\mathrm{CRP}>10 \mathrm{mg} / \mathrm{dL}$ day $0 \mathrm{MV}$} & 1.375 & $0.262-7.220$ & 0.707 \\
\hline \multicolumn{2}{|c|}{$\mathrm{CRP}>10 \mathrm{mg} / \mathrm{dL}$ day $7 \mathrm{MV}$} & 1.429 & $0.297-6.977$ & 0.656 \\
\hline \multicolumn{2}{|c|}{$<500$ lymphocytes day $0 \mathrm{MV}$} & 1.225 & $0.265-5.667$ & 0.795 \\
\hline \multicolumn{2}{|c|}{$<500$ lymphocytes day $7 \mathrm{MV}$} & 3 & $0.269-33.487$ & 0.372 \\
\hline
\end{tabular}

ARDS: acute respiratory distress syndrome, MV: mechanical ventilation, CRP: C reactive protein

One differentiating aspect of our series is the high incidence of co-infection at ICU admission (48.1\%). Following our protocol, $100 \%$ of patients received empiric antibiotic treatment. Similar data were observed in the series by Yang et al. and Barrasa et al. in which $94 \%$ and $88 \%$ of patients received antibiotics $[20,22]$. Conversely, in the Tarragona study no case of coinfection was identified and only $11.6 \%$ of patients received antibiotics at ICU admission. Arentz et al. report an incidence of bacterial and viral coinfection of $4.8 \%$ and $14.3 \%$, respectively. Bhatraju et al. did not find any cases of coinfection despite an active search [24]. It is possible that the differences observed are due to the definition used, including both cultures/serology results and elevation of biomarkers.

We were unable to detect any variable at MV onset that could help us predict worse clinical course either from the point of view of age or comorbidities, or from the viewpoint of inflammatory or respiratory parameters. Hua et al. observed that patients who required MV presented a lower lymphocytes count, and CRP levels were higher [26]. Wang et al. detected that also D-dimer was higher in patients requiring MV [30]. We have observed that patients from group B presented a higher $\mathrm{O}_{2} \mathrm{~A}-\mathrm{a}$ gradient and a lower $\mathrm{pO}_{2} / \mathrm{FiO}_{2}$ ratio after 7 days under MV. Persistence of moderate ARDS after 7 days of MV increases the risk of poor outcome (OR 6.417, Cl 95\% 1.091-37.735, $p=0.040$ ). This finding coincides with that published by Rodriguez et al. who reported that among patients who died, the $\mathrm{pO}_{2} / \mathrm{FiO}_{2}$ ratio did not improve after 7 days of treatment [19]

A notable aspect of our series is the low 28 days mortality rate (7.4\%). Blake et al. presented ICU mortality of 21\% (with 15 of the 39 patients still in the ICU) [21]. In the Italian and the Tarragona series, they also reported ICU mortality of 26\% and 23.3\% (28.1\% among patients who received MV), respectiveIy $[19,25]$. Mortality was significantly higher in the remaining studies: $36 \%$ at 28 days in the Barrasa et al. series [22], $50 \%$ hospital mortality in the Bhatraju et al. [24] and Wang et al. series [30], 52.4\% at 5 days in the Arentz et al. study [23], 61.5\% at 28 days in the Yang et al. series [20] and up to $92 \%$ in patients with MV reported by Hua et al. [26]. This lower mortality does not appear to be related to less severity in our patients. As we have discussed, it is possible that the incidence of non-respiratory organ failure is lower for our patients, however, the respiratory failure is more severe and lasts longer. It could be considered that the reduced number of patients in our series did not entail an exceptional overload for our ICU, but 22 patients requiring MV simultaneously were treated, meaning an occupation of 157\% of the beds usually available for MV. Once we know the results of RECOVERY trial, the use of corticosteroids may have been a reason for this low mortality (although 28 days mortality in mechanical ventilated patients receiving dexamethasone in this trial is $29.3 \%$ ). We believe that some factors such as the experience managing ARDS patients of staff treating these patients, in addition to organization of the COVID-ICU, may have played an important role. However, we would not go so far as to attribute the reduction in our mortality to a specific single aspect.

Our study presents significant limitations. First, the reduced sample size, which hinders detecting possible discrepancies between groups. Second, the high survival observed prevents comparisons of groups based on mortality and led us to use a composite outcome (mortality or prolonged MV). Third, absence of a control group makes it impossible to draw definitive conclusions about methylprednisolone effect. Fourth, this is a single hospital series with some specific characteristics and some solutions applied in our hospital context, which complicates extrapolation of our results to another type of patient or center.

To conclude, our COVID-19 patients presented severe and long lasting ARDS; a short course of low dose corticosteroids appears to reduce the inflammation and temporarily improve the oxygenation. Only persistence of ARDS after 7 days under $M V$ was a predictor of poor outcome. 


\section{ACKNOWLEDGEMENTS}

Authors thank the Illustrious Medical College of Ourense for their collaboration in the English translation of this article

\section{FUNDING}

None to declare

\section{CONFLICTS OF INTEREST}

The authors declare that they have no conflicts of interest

\section{REFERENCES}

1. Bhimraj A, Morgan RL, Hirsch Shumaker A, et al (2020) Infectious Diseases Society of America Guidelines on the Treatment and Management of Patients with COVID-19

2. Alhazzani W, Møller MH, Arabi YM, et al (2020) Surviving Sepsis Campaign: guidelines on the management of critically ill adults with Coronavirus Disease 2019 (COVID-19). Intensive Care Med. doi:10.1007/s00134-020-06022-5

3. Wilson KC, Chotirmall SH, Bai C, Rello J (2020) COVID 19: Interim Guidance on Management Pending Empirical Evidence. From an American Thoracic Society led International Task Force. 12

4. Díaz E, Menéndez RA, Cortés PV, et al (2020) Tratamiento farmacológico de la covid-19: revisión narrativa de los grupo de trabajo de enfermedades infecciosas y sepsis (gteis) y del grupo de trabajo de transfusiones y hemoderivados (gtth). Medicina Intensiva. doi:10.1016/j.medin.2020.06.017

5. Kalil AC (2020) Treating COVID-19-Off-Label Drug Use, Compassionate Use, and Randomized Clinical Trials During Pandemics. JAMA. doi:10.1001/jama.2020.4742

6. Siddiqi HK, Mehra MR (2020) COVID-19 illness in native and immunosuppressed states: A clinical-therapeutic staging proposal. J Heart Lung Transplant 39:405-407. doi:10.1016/j.healun.2020.03.012

7. Sinha P, Matthay MA, Calfee CS (2020) Is a "Cytokine Storm" Relevant to COVID-19? JAMA Intern Med. doi:10.1001/jamainternmed.2020.3313

8. Wu C, Chen X, Cai Y, et al (2020) Risk Factors Associated With Acute Respiratory Distress Syndrome and Death in Patients With Coronavirus Disease 2019 Pneumonia in Wuhan, China. JAMA Intern Med. doi:10.1001/jamainternmed.2020.0994

9. Annane D, Pastores SM, Rochwerg B, et al (2017) Guidelines for the diagnosis and management of critical illness-related corticosteroid insufficiency (CIRCI) in critically ill patients (Part I): Society of Critical Care Medicine (SCCM) and European Society of Intensive Care Medicine (ESICM) 2017. Intensive Care Med 43:1751-1763. doi:10.1007/s00134-017-4919-5

10. Villar J, Ferrando C, Martínez D, et al (2020) Dexamethasone treatment for the acute respiratory distress syndrome: a multicentre, randomised controlled trial. Lancet Respir Med 8:267-276. doi:10.1016/S2213-2600(19)30417-5
11. Torres A, Sibila O, Ferrer M, et al (2015) Effect of corticosteroids on treatment failure among hospitalized patients with severe community-acquired pneumonia and high inflammatory response: a randomized clinical trial. JAMA 313:677-686. doi:10.1001/jama.2015.88

12. Li H, Yang S-G, Gu L, et al (2017) Effect of low-to-moderate-dose corticosteroids on mortality of hospitalized adolescents and adults with influenza $A(H 1 N 1) p d m 09$ viral pneumonia. Influenza Other Respir Viruses 11:345-354. doi:10.1111/irv.12456

13. Arabi YM, Mandourah Y, Al-Hameed F, et al (2018) Corticosteroid Therapy for Critically III Patients with Middle East Respiratory Syndrome. Am J Respir Crit Care Med 197:757-767. doi:10.1164/ rccm.201706-11720C

14. Moreno G, Rodríguez $A$, Reyes LF, et al (2018) Corticosteroid treatment in critically ill patients with severe influenza pneumonia: a propensity score matching study. Intensive Care Med 44:14701482. doi:10.1007/s00134-018-5332-4

15. Lansbury $L E$, Rodrigo $C$, Leonardi-Bee J, et al (2020) Corticosteroids as Adjunctive Therapy in the Treatment of Influenza: An Updated Cochrane Systematic Review and Meta-analysis. Crit Care Med 48:e98-e106. doi:10.1097/CCM.0000000000004093

16. Russell CD, Millar JE, Baillie JK (2020) Clinical evidence does not support corticosteroid treatment for 2019-nCoV lung injury. Lancet 395:473-475. doi:10.1016/S0140-6736(20)30317-2

17. RECOVERY Collaborative Group, Horby P, Lim WS, et al (2020) Dexamethasone in Hospitalized Patients with Covid-19 - Preliminary Report. N Engl J Med. doi:10.1056/NEJMoa2021436

18. ARDS Definition Task Force, Ranieri VM, Rubenfeld GD, et al (2012) Acute respiratory distress syndrome: the Berlin Definition. JAMA 307:2526-2533. doi:10.1001/jama.2012.5669

19. Rodríguez A, Moreno G, Gómez J, et al (2020) INFECCIÓN GRAVE POR CORONAVIRUS SARS-COV-2: Experiencia en un hospital de tercer nivel con pacientes afectados por COVID-19 durante la pandemia 2020. Medicina Intensiva. doi:10.1016/j.medin.2020.05.018

20. Yang $X, Y u Y, X u$ J, et al (2020) Clinical course and outcomes of critically ill patients with SARS-CoV-2 pneumonia in Wuhan, China: a single-centered, retrospective, observational study. Lancet Respir Med. doi:10.1016/S2213-2600(20)30079-5

21. Blake A, Collins $D, O^{\prime}$ Connor $E$, et al (2020) Clinical and biochemical characteristics of patients admitted to ICU with SARS-CoV-2. Med Intensiva. doi:10.1016/j.medin.2020.05.003

22. Barrasa H, Rello J, Tejada S, et al (2020) SARS-CoV-2 in Spanish Intensive Care Units: Early experience with 15-day survival in Vitoria. Anaesthesia Critical Care \& Pain Medicine. doi:10.1016/j.accpm.2020.04.001

23. Arentz $M$, Yim E, Klaff $L$, et al (2020) Characteristics and Outcomes of 21 Critically III Patients With COVID-19 in Washington State. JAMA. doi:10.1001/jama.2020.4326

24. Bhatraju PK, Ghassemieh BJ, Nichols M, et al (2020) Covid-19 in Critically III Patients in the Seattle Region - Case Series. N Engl J Med 382:2012-2022. doi:10.1056/NEJMoa2004500

25. Grasselli G, Zangrillo A, Zanella A, et al (2020) Baseline Characteristics and Outcomes of 1591 Patients Infected With SARS-CoV-2 Admitted to ICUs of the Lombardy Region, Italy. JAMA. doi:10.1001/ 
jama.2020.5394

26. Hua J, Oian C, Luo Z, et al (2020) Invasive mechanical ventilation in COVID-19 patient management: the experience with 469 patients in Wuhan. Crit Care 24:348. doi:10.1186/s13054-020-03044-9

27. Cao B, Wang Y, Wen D, et al (2020) A Trial of Lopinavir-Ritonavir in Adults Hospitalized with Severe Covid-19. New England Journal of Medicine 382:1787-1799. doi:10.1056/NEJMoa2001282

28. Geleris J, Sun Y, Platt J, et al (2020) Observational Study of Hydroxychloroquine in Hospitalized Patients with Covid-19. New England Journal of Medicine 382:2411-2418. doi:10.1056/NEJMoa2012410

29. Tang W, Cao Z, Han M, et al (2020) Hydroxychloroquine in patients with mainly mild to moderate coronavirus disease 2019: open label, randomised controlled trial. BMJ 369:. doi:10.1136/bmj.m1849

30. Wang T, Tang C, Chen R, et al (2020) Clinical Features of Coronavirus Disease 2019 Patients With Mechanical Ventilation: A Nationwide Study in China. Critical Care Medicine Online First: doi:10.1097| CCM.0000000000004473 